\title{
Life Cycle Management in Industry- Supporting Business with Life Cycle Based Assessments
}

\author{
Andreas Bednarz, Julia Beier, Thomas Grünenwald, \\ Birgit Himmelreich, Bärbel Hundt, Florian A. Jaeger, \\ Martin Kirchner, Stephan Krinke, Ulla Létinois, Christina Merz, \\ Lisa Mohr, David Morris, Nikolaj Otte, Gerald Rebitzer, Peter Saling, \\ Urs W. Schenker, Diederik Schowanek, Gerd Vollmer, Niklas von der \\ Assen and Alain Wathelet
}

\begin{abstract}
Sustainability is becoming more and more a strategic growth driver for numerous companies. In this context transparency on the environmental strengths and weaknesses of products and processes and related opportunities and risks is crucial. Accordingly, the assessment of sustainability aspects is gaining importance for companies and their customers along the value chain. Life cycle-based methodologies as Life Cycle Assessment (LCA) but also other assessment systems
\end{abstract}

\footnotetext{
A. Bednarz · B. Himmelreich

Covestro AG, 51373 Leverkusen, Germany

J. Beier

Beiersdorf AG, Unnastraße 48, 20245 Hamburg, Germany

T. Grünenwald · P. Saling ( $\square)$

BASF SE, 67056 Ludwigshafen, Germany

e-mail: peter.saling@basf.com

B. Hundt $\cdot$ N. von der Assen

Bayer AG, 51368 Leverkusen, Germany

F. A. Jaeger

Siemens AG, 80333 Munich, Germany

M. Kirchner · C. Merz

Evonik Technology \& Infrastructure GmbH,

Rellinghauser Straße 1-11, 45128 Essen, Germany

S. Krinke

Volkswagen AG Group Research Environmental Affairs, 38440 Wolfsburg, Germany

U. Létinois
}

DSM Nutritional Products, Process Research, Wurmisweg 576,

4303 Kaiseraugst, Switzerland

L. Mohr

Thyssenkrupp Steel Europe AG, 47166 Duisburg, Germany

(C) The Author(s) 2018

E. Benetto et al. (eds.), Designing Sustainable Technologies,

Products and Policies, https://doi.org/10.1007/978-3-319-66981-6_39 
are used in decision-making processes, product development and marketing activities. Many companies have a public corporate sustainability policy backed up with commitments in the form of quantitative targets. LCA methodology may be used as a tool supporting the identification of 'hot spots' in the value chain and measuring progress towards sustainability targets. In practice, however, common issues and challenges stand in the way of a full deployment of LCA methods in industry. It is important for companies to find common ground on how to implement these approaches, which data and impact assessments to be used and how results should be interpreted. ISO rules give a good basis for that work, though it is not sufficient for several questions. For exchanging experiences, updating or adopting methods, and generating data the International Sustainability Practitioners Network (ISPN) was created in 2012. The ISPN is an exchange forum for LCA methodology in the context of industry and comprises sustainability experts from a range of different industry sectors. To share experiences from the different activities, examples of good practices of this cross-sectoral initiative and to discuss opportunities for improving sustainability assessments within the companies are introduced. This article highlights challenges and solutions in terms of data availability and uncertainty, streamlining and using standardization processes as well as communication of results with non-LCA-experts.

\section{Introduction}

The International Sustainability Practitioners Network (ISPN) is a voluntary and loosely associated network of sustainability experts and/or managers from large industry organizations. It represents diverse product portfolios and its members occupy very different positions in the value chain. The intention of ISPN is to

D. Morris

DSM, Het Overloon 1, 6411 TE Heerlen, Netherlands

N. Otte

Henkel AG \& Co. KGaA, Henkelstrasse 67, 40589 Düsseldorf, Germany

G. Rebitzer

Amcor, Thurgauerstrasse 34, 8050 Zurich, Switzerland

U. W. Schenker

Nestlé Research, Vers-chez-les-blanc, 26, 1000 Lausanne, Switzerland

D. Schowanek

Procter \& Gamble, Brussels Innovation Centre, Temselaan 100, B-1853 Strombeek-Bever, Belgium

G. Vollmer

Merck KGaA, Frankfurter Straße 250, 64293 Darmstadt, Germany

A. Wathelet

Solvay, Research \& Innovation, B-1120 Brussels, Belgium 


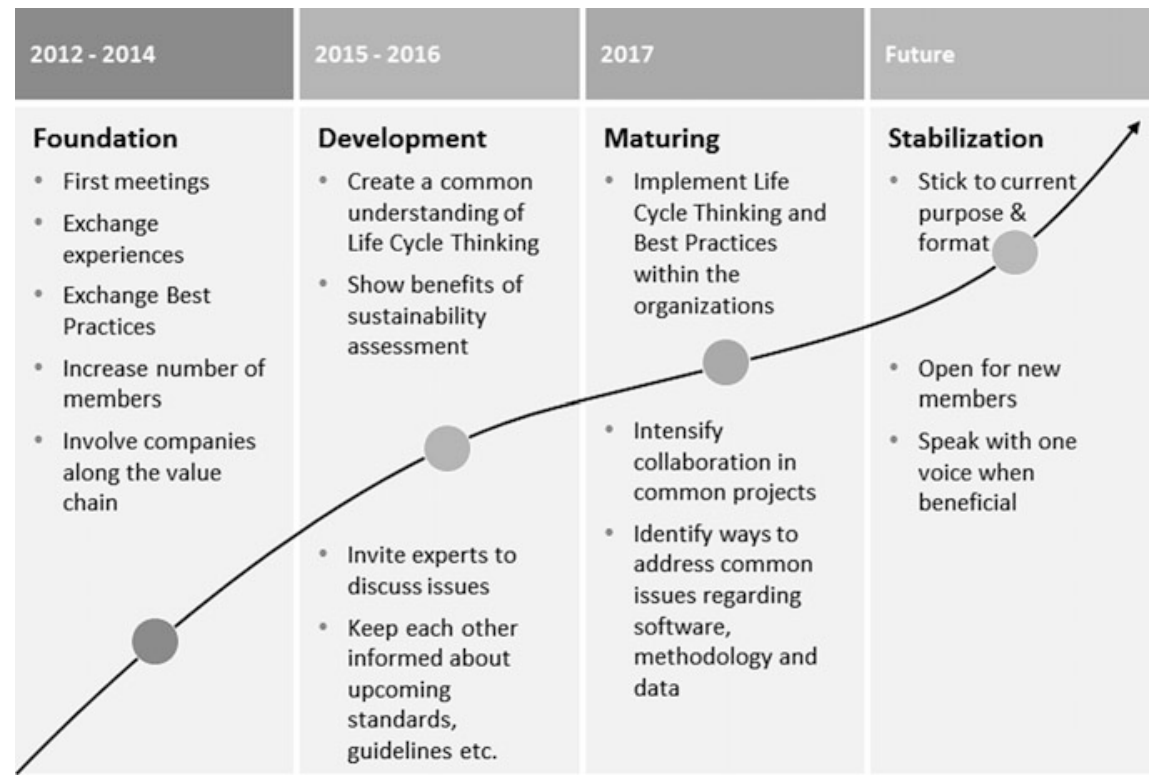

Fig. 1 Development and main focusses of the International Sustainability Practitioners Network (ISPN)

exchange information and successful practices around common aspects in sustainability assessment methodologies, lifecycle thinking and management consulting. In addition, the ISPN aims at fostering Life Cycle Assessment (LCA) as a tool to support sustainable innovation and measurement. The development and common understanding of the ISPN and its function is illustrated in Fig. 1. Participating in the ISPN serves as source of inspiration for its members and helps them to implement and disseminate Life Cycle Thinking and Best Practices regarding sustainability assessment within their organization.

Since its start the International Sustainability Practitioner Network (ISPN) gained more and more members and currently consists of 15 companies from various sectors and countries as shown in Fig. 2.

\section{LCA and Other Approaches for the Assessment of Sustainability}

Although each member company uses slightly different approaches to assess its sustainability performance, the basic idea of applying LCA in decision making and as communication tool is very similar across companies and industrial sectors. Simplified LCA approaches as well as Hotspot Analysis are of particular interest within the early research and development phase or during the Eco-design of a product, service or process. In addition, LCA is used in marketing and 


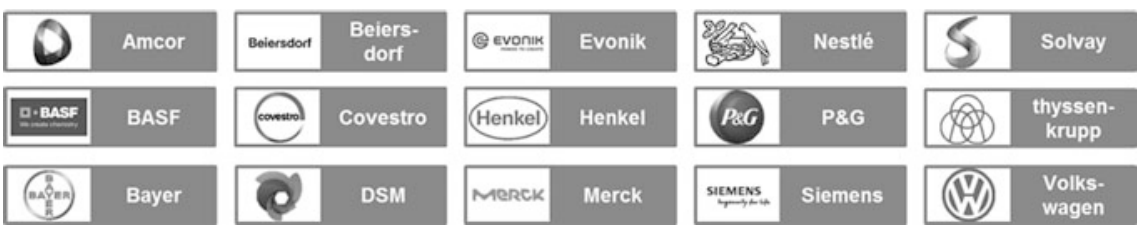

Fig. 2 ISPN members 2017

communication to inform customers, consumers, regulatory authorities or other stakeholders about the sustainability performance of a product, service or process. However, the areas of LCA applications are not strictly separated, i.e. a simplified LCA or a Hot-Spot Analysis needed in a decision-making process can be extended to a full LCA study for marketing and communication or a full LCA study performed for marketing can support decision making processes.

One example of such a process is shown in Fig. 3 where a sustainability evaluation is included in the Covestro stage-gate process for decision making and documentation in research and development projects. The methodology for sustainability assessment shown in Fig. 3 presents the increasing depth in sustainability evaluation in the advancing process design.

During the process design in the initial step a "Hotspot Identification" is carried out. It helps $R \& D$ departments to steer their activities in the direction of more sustainable product solutions in early development phases and without too much needs for information.

In the next phase the obtained Hotspots can lead to a more detailed analysis. Based on the results, the conduction of a Screening LCA or an update of the

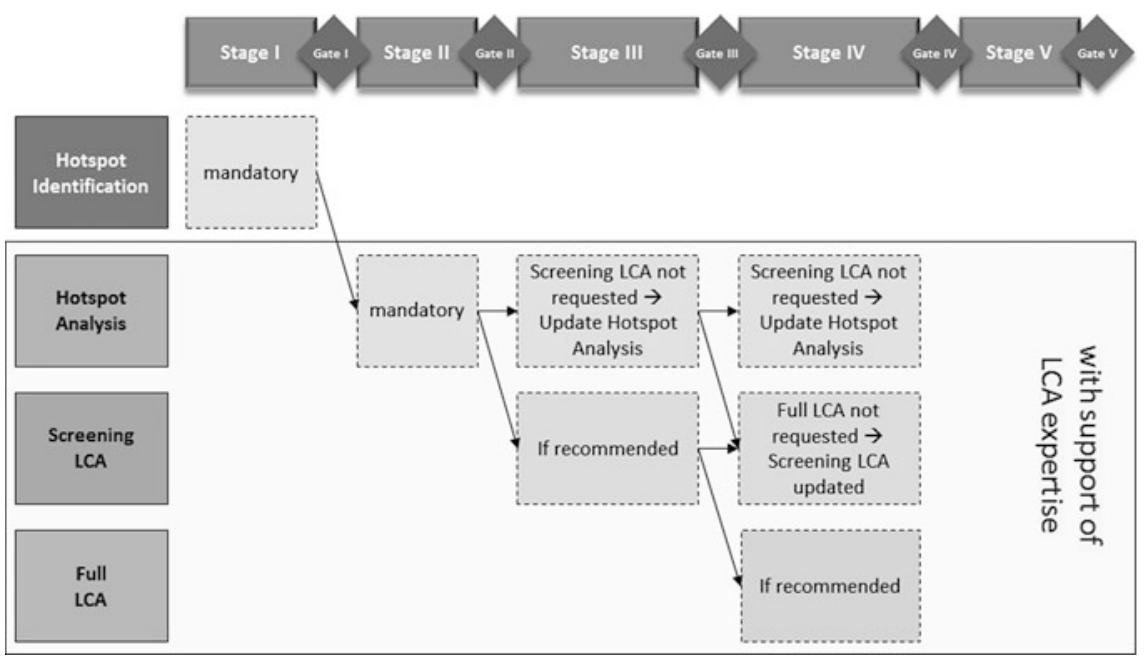

Fig. 3 Covestro stage-gate process for a systematic sustainability assessment during process design 
"Hotspot Analysis" is recommended for the next stage. A reason for such a recommendation can be unclear or probably negative results during the Hotspot Analysis to enhance the decision making. This might lead to the cancellation of such projects if they are not sustainable. On the other hand, a hotspot analysis may also reveal a potential unique selling point, which must be confirmed by a full LCA prior to market launch.

Successfully applied to the innovation process, LCA approaches help to steer towards given sustainability targets and can form a valuable basis for the companies' sustainability strategy. Such methods enable an overall assessment and the determination of the most significant processes and products for a successful development. Examples for a successful implementation of such methodologies in industry are the Sustainable Solution Steering ${ }^{\circledR}$ by BASF [1, 2], the Sustainable Portfolio Management by Solvay [3], the Company Footprint by $\mathrm{P} \& \mathrm{G}$ and $\mathrm{I} 2 \mathrm{P}^{3 \circledR}$ (Idea-to-People-Planet-Profit) by Evonik [4]. BASF assessed more than 65,000 product solutions to identify the most sustainable solutions and to promote those "Accelerators" in the business. Evonik's innovation unit, Creavis, manages its

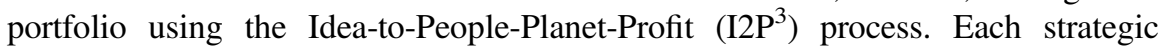
research project is assessed on the basis of environmental influences (planet) and societal aspects (people) as well as economic criteria (profit).

Solvay Sustainable Portfolio Management (SPM) tool enables a global and systematic assessment of more than $80 \%$ of the business portfolio revenue every year, a fact based and robust compass to steer Solvay's portfolio toward better business because it is more sustainable with 9\% growth, year-to-year, for Sustainable Solutions. Similar to the Solvay approach, P\&G's Company Footprint identifies 'Hotspots' for the whole company by multiplying the life cycle impacts (such as energy demand, $\mathrm{CO}_{2}$-emissions, water use or eutrophication) for a given product category and a life cycle stage with the sales. The results are then used to decide about the biggest opportunities for environmental improvement, and about the key actors along the value chain who have the biggest impact on the improvement, e.g. suppliers, production plants, transportation or consumers. This knowledge can be used in general to steer the product portfolio of the entire company. Since $P \& G$ found out that the biggest footprint is the energy used when consumers heat the water for their laundry, they expanded and improved their cold washing products. In the logic of this portfolio steering approach, a small change on a mega brand or category can be overall more effective for the environment than major design changes in small brands.

\section{Challenges of Data Exchange in the Value Chain}

To improve the quality of sustainability assessments and to close data gaps along the value chain in situations where no industry averages from associations are available an inter-company data exchange is needed. Thus, member companies already started to collaborate on common LCA projects which involve exchange of 
data and information along the value chain. Several formats for data exchange that allow for the protection of Intellectual Property (IP) already exist, but still the data exchange across different software tools and the harmonization of methodologies remain issues which will be further outlined here.

Each company in a value chain generally owns accurate information about processes bound to its own operations, but faces a lack of information when it comes to manufacturing steps or application of products outside of its operations. Commercial or public LCA databases, providing generic information are one valuable source to overcome data gaps for the coverage of all relevant life cycle stages. Depending on the requirements for data quality this source of generic information may not be sufficient as the sheer number of existing raw materials, intermediates, processes and applications in reality makes it unlikely that good quality data will be available for most specific product systems. This challenge grows when proceeding in the value chain.

Thus, an exchange of data among partners in a value chain seems a viable solution in terms of data coverage and quality. Two specific problem areas were identified for a successful data exchange, both discussed in the following sections.

One issue relates to data format to be used for exchanges, another one to the exchange process and harmonization in the data exchange itself.

\subsection{Data Formats}

The application of LCA depends on the availability of data to build reliable inventories. Data- demand and dependency are determined by the position of a company in the value chain as discussed above. For cradle-to-gate assessments, early value chain users are less dependent on external data and can invest their time into the analysis of internal processes, while late value chain users have to complement their own data with pre-catalogued values from databases or from their suppliers to cover the purchased raw material and utility inputs. To avoid using generalized datasets (proxies) from commercial databases, exchange of LCA information between companies is considered as an added value for the improvement of data quality in LCA. Nevertheless, this exchange is not a standard process by now.

As an important obstacle in exchanging LCA data the need for protection of IP has been identified. LCA data has sometimes been suspected to enable retro-analysis of the underlying processes, thus violating the requirements of IP protection.

Depending on how data is to be exchanged this problem might be alleviated. LCA data could be exchanged in three different formats:

- Unit process data

- Aggregated process data

- Impact indicator results 
Unit process data make the production processes of an enterprise completely transparent. To that end there will be confidentiality issues for companies who employ (A) sensitive processes or (B) wish to keep their supply chain confidential. Traceability will play a role in the future for some sectors such as the energy sector. Unit process data are one way of transferring such information, while keeping flexibility.

Aggregated process data provides a reasonable level of confidentiality, as it converts the mass and energy balance for the production of the evaluated product to elementary flows which don't allow any back tracking to company specific data. The aggregated data may be used by other LCA practitioners to calculate any given impact indicator in the scope of the dataset. To that end aggregated process data provide flexibility in the assessment and protect IPs. As additional information, this aggregated dataset could be completed (or not) with metadata describing some parts of the process or modelling hypothesis like allocation rules, etc.

Impact indicator results contain the least detailed information about any process when exchanged between value chain partners. If a "fingerprint" set of indicators was defined, this set of indicators would enable calculation of all relevant environmental impacts of derived products, but mainly outside of commercial LCA tools. Since the indicators are not so transparent, a detailed guideline in the calculation of such indicators is required. The advantage of impact indicators is the application of unambiguous assessment once rules for scope have been defined. Their easy tabulation enables rapid transfer and data warehousing. The ideal format for data exchange does not exist and depends on the demands of the involved parties. If a standardized set of indicators is used such as those recommended by the Product Environmental Footprint (PEF), then exchanging these indicator results may provide sufficient information. Such exchange would not allow further investigation of environmental flows or calculation of customized impact indicators. Also, current software tools typically run on aggregated process data for unit process data. Implementing a combination of impact indicators in conjunction with process data in LCA software is not easy to handle and would not work to be a currently viable solution.

Difficulties occurring during the exchange process are often caused by different LCA software used and are therefore somehow out of the direct influence of such companies.

\subsection{Data Exchange}

Companies that want to exchange LCI or LCA data often do not run the same LCA software or data storage platform. Several examples were experienced where such an exchange failed or led to imprecise results due to inconsistency in environmental flow definitions or different implementation of LCIA methods. 
Examples of issues that lead to such problems:

- Naming of environmental flows in different datasets varies

- Amount and naming of compartments for flows differ between databases/ software systems

- Application of substance specific characterization factors in different software is not the same

Matching of flows between different software systems is not precise, since one software type calculates with five different characterization factors (CF's) for eight (sub-) compartments, whereas the alternative software only considers three different CF's for three compartments. Thus, for example, the eco-toxicity impact of the same substance can vary significantly depending on the type of software/database used (Table 1). Unfortunately, this problem also appears for publicly available industry averages which are evaluated with different software tools.

From a comprehensive value chain perspective, it is desirable to have a common database format facilitating the exchange of data between different LCA systems. In the meantime, a continuous effort by an independent arbitrator could help perpetuate consistency of the data format and increased coverage of flows (typically, "mapping file") which should be implemented in all common LCA software tools to enable harmonized data exchange.

\section{Methodological Issues}

Methodological issues of Life Cycle Assessment are one of the main reasons why LCA is not more widely applied for sustainability assessments in industry and policy today. On the one hand, methodological issues sometimes make it difficult to identify and properly apply the most appropriate way of assessing a given product

Table 1 Example eco-toxicity of chromium VI: differences for the same flow in different databases $(\mathrm{CF}=$ characterization factor)

\begin{tabular}{l|l|l|l|c}
\hline Element & Compartment & Sub-compartment & CF's software 1 & \multirow{2}{*}{ CF's software 2 } \\
\hline \multirow{3}{*}{ Chromium (+VI) } & Air & Low population & 42,140 & \multirow{2}{*}{41,972} \\
\cline { 2 - 4 } & Air & High population & 41,800 & \\
\cline { 2 - 4 } & Air & Unspecified & 41,970 & \\
\cline { 2 - 4 } & Soil & Unspecified & 52,560 & 52,555 \\
\cline { 2 - 4 } & Water & Ground-, long-term & 52,560 & \multirow{2}{*}{104,644} \\
\cline { 2 - 4 } & Water & River & 104,600 & \\
\cline { 2 - 4 } & Water & Ground & 52,560 & \\
\cline { 2 - 4 } & Water & Unspecified & 104,600 & \\
\hline
\end{tabular}


or system. On the other hand, different methodological choices between actors (or stakeholders) in a supply chain or product system make it difficult to find consensus and agree on common metrics, which decreases the confidence level of the end user and decision maker in LCA as a tool.

Many review studies have compiled the most important methodological issues that remain open in LCA today. That was done e.g. in the program Sustainable Process Industry through Resource and Energy Efficiency "SPIRE" with the specific projects Sustainability assessment methods and tools project "SAMT" and Metrics for Sustainability Assessment in European Process Industries "MEASURE" in 2016, with ISPN members contribution [5]. For every industry sector, the key methodological issues are different: for example, while allocation between co-products is a key issue in the food industry and the waste sector, methods to assess (eco-) toxicity are of paramount importance for the chemicals or pharmaceuticals sector. The methodological issues of high relevance for industry can be positioned in the four phases of LCA (as defined by the ISO standards 14040 and 14044-Table 2).

The development of novel or improved guidance or standards on methodological issues needs a proper governance model; including stakeholder outreach and consultation (cf. the process applied to the development of new ISO standards). This cannot be done in the context of an informal network such as the ISPN, and also needs a proper process by which stakeholders outside the industry can be reached. Therefore, ISPN has not attempted to provide guidance or develop standards on methodological issues of LCA. Instead, a selection of key external initiatives was identified which published suggestions for it (see Fig. 4), and have decided to follow and engage in those processes. Standards and guidance processes are often industry-specific, the ISPN offers an opportunity for a given industry sector to better understand the working of other industry sectors.

While ISPN as an organization cannot take credit for the methodological advancements that have been achieved over the past years in LCA, most of the members have been involved in the development and consultation processes of influential guidance documents and standards. In ISPN, those experts have presented the most relevant methodological advancements, and ISPN has discussed the implications of these for the respective companies and industry sectors that we

Table 2 Examples of key environmental issues in LCA, currently being worked by industry, classified as per the ISO 14040 \& 14044 standards

\begin{tabular}{|c|c|c|c|}
\hline Goal and scope & LCI & LCIA & $\begin{array}{l}\text { Interpretation } \\
\text { (communication) }\end{array}$ \\
\hline $\begin{array}{l}\text { - EU PEF [6] } \\
\text { horizontal } \\
\text { methodological } \\
\text { issues (e.g. } \\
\text { granularity) }\end{array}$ & $\begin{array}{l}\text { - Data } \\
\text { availability/ } \\
\text { access } \\
\text { - Data quality } \\
\text { - EU PEF } \\
\text { horizontal } \\
\text { issues }\end{array}$ & $\begin{array}{l}\text { - Consensus on impact } \\
\text { methods e.g. (Eco-) } \\
\text { Toxicity, near-far } \\
\text { field impacts/ } \\
\text { nutritional benefits, } \\
\text { Land-use/biodiversity } \\
\text { aspects, Water } \\
\text { consumption) } \\
\text { - Normalization and } \\
\text { weighting }\end{array}$ & $\begin{array}{l}\text { - Hot spot analysis } \\
\text { recommendation } \\
\text { - Suitable B2B/B2C } \\
\text { approaches }\end{array}$ \\
\hline
\end{tabular}




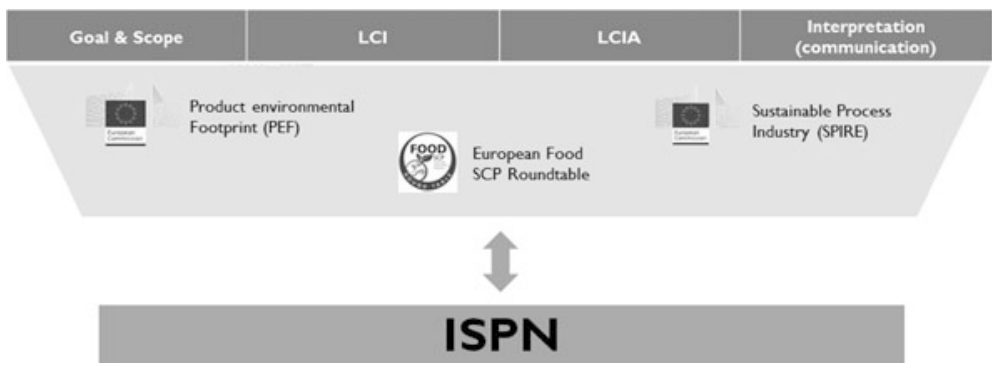

Fig. 4 Schematic overview of relevant organizations working on standardization and guidance for different parts of a LCA

represent. In that sense, the ISPN plays an important role for the methodological advancement of LCA and for the dissemination of methodological developments among experienced industry practitioners.

\section{$5 \quad$ Vision and Mission}

The members of the ISPN have concluded that there are commonalities and differences in the interests and approaches of the participants, due to the diversity of the group and the respective industry sectors. The ISPN conceptualized why already the understanding and thus concepts and practical approaches can be different. However, we consider a common understanding to be the key to the success of a sustainability life cycle thinking in large corporations. We believe the ISPN platform serves as a good starting point to foster such a common understanding of methodologies $[7,8]$.

For exchanging experiences, updating or adopting methods, and generating data the ISPN was created several years ago. The ISPN is an exchange forum for LCA methodology in the context of industry and comprises sustainability experts from a range of different industry sectors. To share experiences from the different activities, the presentation will give examples of good practices of this cross-sectoral initiative and discuss opportunities for improving sustainability assessments within of companies.

To give this basic approach a more precise frame and guidance for interested parties on how this network works together and how others can benefit from the ISPN, we started to develop a "Vision and Mission" section linked with a frame that show which aspects will be covered by the work of ISPN.

It can be summarized in the following overview:

\section{Vision}

- Leadership of cross-sectoral industry LCA experts

- High recognition by academia, government and industry

- Effective platform for collaboration on methods, tools and data 


\section{Mission}

- We facilitate exchange platforms of LCA experts discussing aspects of methods, tools and data

- We identify and prioritize relevant topics of cross-sectoral challenges in the field of sustainability assessments

- We collaborate on projects or method developments with academia, authorities, NGOs and other industry partners

- We extend the collaboration platform to new sectors taking their experiences and needs into account

- We recommend and suggest changes in methodologies, data management and tools

- We discuss and communicate our experiences with other practitioners' groups

- We work together effectively and with smart solutions

- We intensify networking activities and offer a broad cross-sectoral expertise

To cluster different work packages and to find out, which opportunities can be achieved by the ISPN, different topics and activities were identified. The cross-sectoral approach of ISPN allows the link of different experiences in the field of the assessment of sustainability as a starting point. The single companies work together and act as one organization defining needs and opportunities for a successful sustainability measurement. It gives guidance and defines good practices for the integration of the findings into the business and into business decision-making $[9,10]$.

Four activities were identified as a basis for suggesting changes and improvements of tools, methods and data systems. These four activities are using the extended expertise of the members, the exchange of experiences over the last decade, modes of collaboration in defining needs, requirements, pathways for improvement etc. The recognition by other practitioners, academia or NGOs for the ISPN will support the transportation and communication of important needs of different fields for further improvements. It shows that leading companies in the field of sustainability assessment can initiate and foster the development of new, modern, easy to use, applicable tools, methods and data sets [11, 12].

With this approach, the ISPN can support funded projects, standard generation, definition of basic requirements for sustainability assessments and of common practices. These findings will be publicly available and can be used for further improvement. Based on these findings, the ISPN can improve its way of collaboration, the definition of further topics and areas of improvements. In collaboration with other groups, new developments can be assessed, checked and be proven for applicability in different sectors (Fig. 5). 


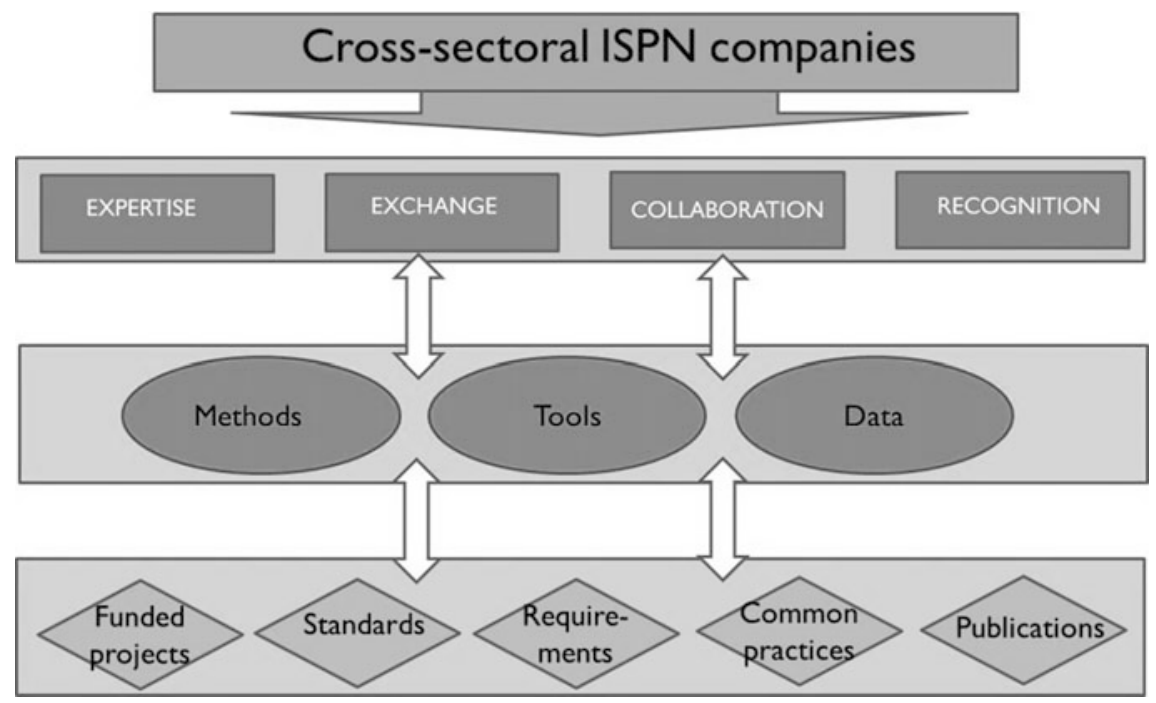

Fig. 5 Overview of processes and activities of ISPN

\section{References}

1. http://rd.springer.com/chapter/10.1007/978-94-017-7221-1_10\#page-1 (Accessed 31.05. 2017).

2. http://eman-eu.org/wp-content/uploads/2016/04/Proceedings_EMAN_2015_BridgingCorporate-and-Academic-Contributions.pdf\#page=42 (Accessed 31.05.2017).

3. http://www.solvay.com/en/company/sustainability/sustainable-portfolio-management/index. html (Accessed 31.05.2017).

4. http://corporate.evonik.de/_layouts/Websites/Internet/DownloadCenterFileHandler.ashx? fileid=3683 (Accessed 31.05.2017).

5. https://www.spire2030.eu/sites/default/files/users/user355/SAMT_D.1.1_final_updatedlinks_ Dec2016.pdf (Accessed 31.05.2017).

6. http://ec.europa.eu/environment/eussd/smgp/product_footprint.htm (Accessed 30.05.2017).

7. Herrmann C, Ganzheitliches Life Cycle Management: Nachhaltigkeit und Lebenszyklusorientierung in Unternehmen, VDI Buch, 1st Ed., Springer-Verlag Berlin Heidelberg, 2010.

8. Baitz M, Albrecht S, Brauner E, Broadbent C, Castellan G, Conrath P, Fava J, Finkbeiner M, Fischer M, Fullana i Palmer P, Krinke S, Leroy C, Loebel O, McKeown P, Mersiowsky I, Möginger B, Pfaadt M, Rebitzer G, Rother E, Ruhland K, Schanssema A, Tikana L, LCA's theory and practice: like ebony and ivory living in perfect harmony? J Life Cycle Assess (2013), Vol 18, 5-13.

9. WRI, WBCSD, Corporate Value Chain (Scope 3) Accounting and Reporting Standard: Supplement to the GHG Protocol Corporate Accounting and Reporting Standard, World Resources Institute and World Business Council for Sustainable Development, 2011.

10. Ehrlenspiel K, Kiewert A, Lindemann U, Mörtl M, Kostengünstig entwickeln und konstruieren: Kostenmanagement bei der integrierten Produktentwicklungen, 7th Ed., Springer-Verlag Berlin Heidelberg, 2014. 
11. Russo M.V, Fouts P.A, A Resource-Based Perspective On Corporate Environmental Performance And Profitability, Academy of Management Journal, Vol. 40, No. 3, 1997, 534559.

12. Hart S.L, Ahuja G, Does it pay to be green? An empirical examination of the relationship between emission reduction and firm performance, Business Strategy and the Environment, Vol. 5, 1996, 30-37.

Open Access This chapter is licensed under the terms of the Creative Commons Attribution 4.0 International License (http://creativecommons.org/licenses/by/4.0/), which permits use, sharing, adaptation, distribution and reproduction in any medium or format, as long as you give appropriate credit to the original author(s) and the source, provide a link to the Creative Commons license and indicate if changes were made.

The images or other third party material in this chapter are included in the chapter's Creative Commons license, unless indicated otherwise in a credit line to the material. If material is not included in the chapter's Creative Commons license and your intended use is not permitted by statutory regulation or exceeds the permitted use, you will need to obtain permission directly from the copyright holder.

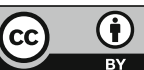

